\title{
Cation effect on the (PEG $8000+$ sodium sulfate) and (PEG 8000 + magnesium sulfate) aqueous two-phase system: Relative hydrophobicity of the equilibrium phases
}

\author{
Kamila Wysoczanska ${ }^{a}$, Sara C. Silvério ${ }^{\mathrm{b}}$, José A. Teixeira ${ }^{\mathrm{b}}$, Eugénia A. Macedo ${ }^{\mathrm{a}, *}$ \\ ${ }^{a}$ LSRE - Laboratory of Separation and Reaction Engineering - Associate Laboratory LSRE/LCM, Faculdade de Engenharia, Universidade do Porto, Rua Dr. Roberto Frias, $4200-465$ \\ Porto, Portugal \\ ${ }^{\mathrm{b}}$ CEB - Centre of Biological Engineering, University of Minho, Campus de Gualtar, 4710-057 Braga, Portugal
}

\section{A R T I C L E I N F O}

\section{Article history:}

Received 23 April 2015

Received in revised form 30 July 2015

Accepted 11 August 2015

Available online 20 August 2015

\section{Keywords:}

ATPS

DNP amino acids

Partitioning

PEG

Salts

\begin{abstract}
A B S T R A C T
The partitioning of four dinitrophenylated (DNP-) amino acids in aqueous two-phase systems of (polyethylene glycol (PEG)-8000 + sodium sulfate) and (polyethylene glycol (PEG)-8000 + magnesium sulfate) in five different tie-lines was experimentally determined at $T=298.15 \mathrm{~K}$. The Gibbs energy of transfer of a methylene group between the two phases was calculated from the measured partition coefficients. This characterizes the relative hydrophobicity of the equilibrium phases. Values of $\Delta G^{*}\left(\mathrm{CH}_{2}\right)$ were in range from $(-0.674$ to -1.012$) \mathrm{kJ} \cdot \mathrm{mol}^{-1}$. A comparison of both systems was carried out. The results show that the cation type has a strong influence on the amino acids partitioning process. The largest relative hydrophobicity was noted for the ATPS system formed by sodium sulfate. This showed to be a better system for the separation.
\end{abstract}

(c) 2015 Elsevier Ltd. All rights reserved.

\section{Introduction}

Aqueous two phase partitioning is a separation technique, with very low environmental impact, considered as an accurate and very adequate methodology for purification of biomolecules $[1,2]$. Although it presents many advantages over other conventional separation processes, it is still not widely implemented at an industrial level, as the understanding of the phenomena that rules the partition is highly complex and still under study. Due to the high content of water, it provides a mild environment with a rare loss of biomolecular activity to these kinds of components. Furthermore, the technique has been extensively studied as it offers substantial advantages, such as biocompatibility, low interfacial tension, high capacity and yield, ease of up-scale [3]. So far, studies have been conducted on the two major types of aqueous two phase systems (ATPS): formed by mixing two solutions of different polymers and of a polymer and a salt. Polyethylene glycol (PEG) is a widely used polymer that, with another polymer or salt, can form two immiscible phases [4], and also, as reported in the literature [5], can enhance protein refolding and decrease aggregation. Systems formed by a polymer and a salt are usually more adopted

\footnotetext{
* Corresponding author.

E-mail address: eamacedo@fe.up.pt (E.A. Macedo).
}

due to the larger difference in densities, higher selectivity, lower viscosity, and the lower cost of salts compared to polymers [6].

Throughout the literature it is possible to find research works on phase separation in ATPS formed by PEG of different average molecular weights and inorganic salts [7-9], such as phosphates [10-12], carbonates [13,14], chlorides [15] and sulfates, e.g. $\mathrm{Na}_{2} \mathrm{SO}_{4}$ or $\mathrm{MgSO}_{4}$ [16-19]. Molecular weight of the polyethylene glycol has a strong impact on the partitioning process [20]. When the molecular weight of polymer is higher, its concentration required for separation by ATPS is lower [21]. Physicochemical characterization and thermodynamic studies on equilibrium phase for two biphasic systems composed of (PEG 8000 + sodium sulfate) and (PEG 8000 + magnesium sulfate) in different conditions of temperature were reported previously $[6,7,22]$. Several works presenting these experimental (liquid + liquid) equilibrium studies and phase diagrams for different compositions are available in the literature.

Although aqueous two phases systems of PEG 8000 and sulfates, $\mathrm{Na}_{2} \mathrm{SO}_{4}[23,24]$ and $\mathrm{MgSO}_{4}[25]$ are mentioned in the literature to be very adequate for bioseparation processes, among others due to the possibility to obtain large two phase region with well-defined interface [6], partitioning in these ATPS's is still not fully investigated.

As the amino acids are precursors of many biomolecules, they can be used to characterize biomonomers, polypeptides and proteins. Therefore, their separation by ATPS is of particular impor- 
tance. Partitioning of amino acids in system of (PEG $8000+\mathrm{Na}_{2}-$ $\mathrm{SO}_{4}$ ) has been evaluated before [26-28], where distribution coefficients for tie-lines with different compositions of salt and polymer were obtained and the relative hydrophobicity of the phases was determined. The authors reported that there is a linear relationship between the relative hydrophobicities and the phase composition. The average number of methylene groups of the aliphatic side chain of the amino acids, adequate for hydrophobicity characteristics, was optimized in [29] and applied later in [30,31].

The experimental data available in the literature for amino acids partitioning in the system (PEG $8000+\mathrm{MgSO}_{4}$ ) is very scarce. Eiteman and Gainer [32] pointed out the dissimilarities of the two phases forming components, which leads to a high $\Delta G\left(\mathrm{CH}_{2}\right)$, and the mildly buffering properties of the salt, that allow to obtain solutions with different concentrations, with slight changes in $\mathrm{pH}$. These experiments concluded that the partition coefficients are proportional to the composition changes between phases. These data were used to explore the relative hydrophobicities of amino acids and the results were applied in further research works concerning hydrophobicity calculations for peptides.

In this work, partition coefficients of four amino acids: $n$ - $(2,4-$ dinitrophenyl)-glycine, $n$-(2,4-dinitrophenyl)-L-alanine, $n$-(2,4dinitrophenyl)-DL-norvaline, $\quad n$-(2,4-dinitrophenyl)-DL-norleucine were experimentally obtained at $T=298.15 \mathrm{~K}$, in five different tie-lines [6], in the aqueous two phase systems: (PEG 8000 + sodium sulfate), (PEG 8000 + magnesium sulfate). The relative hydrophobicities of the phases were investigated based on the calculations of the free energy of transfer of a methylene group between the phases. Polyethylene glycol was chosen as it has many advantages: low toxicity, low volatility and biodegradability, infrequent occurrence of unwanted side reactions. This polymer is extensively reported in the literature [33] and knowledge about its toxicological properties is well documented comparing to the other alternative solvent systems. PEG can have also impact on increasing the solubility of less polar species. This is, to our best knowledge, the first study which compares the hydrophobicity of the phases for these both systems during the partitioning process of the amino acids. Besides the former publication [32], there is no recent work presenting $\Delta G$ calculations for the system - (PEG $8000+\mathrm{MgSO}_{4}$ ). Moreover, there are just two recent publications about amino acids partitioning in the system of (PEG $8000+\mathrm{Na}_{2}-$ $\mathrm{SO}_{4}$ ) which include this hydrophobicity study.

\section{Experimental section}

\subsection{Materials}

Polyethylene glycol (PEG) 8000 (LOT SLBJ5906V), with an average molecular weight $\left(M_{w}\right)$ of 8000 , and magnesium sulfate $\left(\mathrm{MgSO}_{4}\right.$, anhydrous, $\left.\geqslant 99,5 \%, M_{w}=120,37 \mathrm{~g} / \mathrm{mol}\right)$ were purchased from Sigma-Aldrich. Sodium sulfate $\left(\mathrm{Na}_{2} \mathrm{SO}_{4}\right.$, anhydrous, $\geqslant 99.0 \%$, $M_{w}=142.04 \mathrm{~g} / \mathrm{mol}$ ) was supplied by Merck. Stock solutions of each chemical were prepared in deionized water and the concentrations were obtained gravimetrically after lyophilization (Scan Vac, CoolSafe 55-4) for PEG 8000 (50 wt\%) or after evaporating on a heating plate (Stuart hot plate SB300) for sodium sulfate (26 wt\%) and for magnesium sulfate (27 wt\%).

Dinitrophenylated (DNP)-amino acids: $n$-(2,4-dinitrophenyl)glycine (DNP-Gly), $n$-(2,4-dinitrophenyl)-t-alanine (DNP-Ala), $n$-(2,4-dinitrophenyl)-DL-norvaline (DNP-NVal), n-(2,4dinitrophenyl)-DL-norleucine (DNP-NLeu) were purchased from sigma and research organics. For dilutions purposes and to prepare solute solutions ( $0.2 \mathrm{wt} \%$ ), deionized water was used.

All products were used as received without further purification. The purities of the components, and suppliers, are presented in table 1. All weighting was carried out on an Adam Equipment balance model AAA250L, with precision of $\pm 0.2 \mathrm{mg}$.

\subsection{Methods}

Aqueous two phase systems were prepared by weighing the appropriate amounts of polymer - PEG 8000 and salt - $\mathrm{Na}_{2} \mathrm{SO} 4$ $\mathrm{MgSO}_{4}$ stock solutions and adding adequate amounts of water (total mass $1 \mathrm{~g}$ ). Feed compositions of the five tie-lines used for the partitioning studies are specified in table 2. All components were added using an automatic pipette (Multipipette ${ }^{\circledR}$ XStream, Eppendorf). For each tie-line, six replicates with the same feed, but having from (0 to 100) $\mathrm{mg}$ of solute (DNP-amino acid) stock solutions were prepared (mass ratio of DNP-amino acid to total mass from $4 \times 10^{-5}$ to $\left.2 \times 10^{-4}\right)$. To maintain the system composition constant, the corresponding amount of water, from (100 to 0 ) $\mathrm{mg}$, was added. After addition of all components, tubes were intensively shaken on a vortex mixer for 2 min. Phase separation was achieved by centrifugation (Minispin, Eppendorf) at $13.4 \times 10^{3} \mathrm{rpm}$ for $15 \mathrm{~min}$. To ensure complete phase separation, the biphasic systems were incubated for approximately $2 \mathrm{~h}$ at room temperature, $298.15 \mathrm{~K}$, controlled with air conditioning. Subsequently, samples of each phase were withdrawn and conveniently diluted with water. For solute quantification in the top and bottom phases, absorbance measurements were done at $362 \mathrm{~nm}$ using UV-Vis spectrophotometer (Thermo Scientific Varioskan Flash). Partition coefficients $(K)$ for four DNP-amino acids were obtained as the slope of the straight lines representing the absorbance in the top phase versus the absorbance in the bottom phase, both corrected with the respective dilution factors, featured as a fraction of final volume to initial volume $(D F)$ :

$K=\frac{A b s(\text { top }) \cdot D F_{\text {top }}}{A b s(\text { bottom }) \cdot D F_{\text {bottom }}}$,

The methodology used for these calculations was previously reported and discussed by Silvério et al. [31].

\section{Results and discussion}

The feed composition and the partition coefficients obtained for the four DNP-amino acids in the five different tie-lines previously reported in the literature [6] are presented in table 2 . The partition coefficients, $K$, were calculated using equation (1), as described in the previous section. Standard deviations of the mean for the partition coefficients are below $1.90 \mathrm{wt} \%$ (average $1.20 \mathrm{wt} . \%$ ) for the system with sodium sulfate and below $1.53 \mathrm{wt} \%$ (average $1.00 \mathrm{wt}$ $\%$ ) for the system with magnesium sulfate. In all cases, straight lines obtained from the representation of the absorbance in the top phase against the absorbance in the bottom phase, for the six replicates with different composition, present coefficients of determination $r^{2} \geqslant 0.9980$, and average $r^{2}=0.9993$. The partition coefficients are the slope of the following straight lines:

$A b s($ top $)=K \cdot A b s($ bottom $)+b$.

TABLE 1

Products purities.

\begin{tabular}{lll}
\hline Product & Supplier & Purity (\%) \\
\hline Sodium sulfate & Merck & $\geqslant 99.0$ \\
Magnesium sulfate & Sigma-Aldrich & $\geqslant 99,5$ \\
N-(2,4-dinitrophenyl)glycine & Sigma & $\geqslant 99$ \\
N-(2,4-dinitrophenyl)-L-alanine & Research organics & $\geqslant 97$ \\
N-(2,4-dinitrophenyl)-DL-n-valine & Sigma & $\geqslant 97$ \\
N-(2,4-dinitrophenyl)-DL-n-leucine & Research organics & $\geqslant 97$ \\
\hline
\end{tabular}


TABLE 2

Partition coefficients obtained for four DNP-amino acids at $T=298.15 \mathrm{~K}$ and $p=0.1 \mathrm{MPa}$. ${ }^{a}$ Tie-line data from reference [6].

\begin{tabular}{|c|c|c|c|c|c|}
\hline Tie line & I & II & III & IV & V \\
\hline \multicolumn{6}{|c|}{$(P E G+$ sodium sulfate $)$} \\
\hline \multicolumn{6}{|c|}{ Composition $\% w / w[6]$} \\
\hline \multicolumn{6}{|c|}{ Overall } \\
\hline Salt & 7.51 & 8.03 & 8.51 & 9.01 & 9.49 \\
\hline PEG & 14.02 & 15.00 & 16.01 & 17 & 18.02 \\
\hline \multicolumn{6}{|c|}{ Top phase } \\
\hline Salt & 2.486 & 2.176 & 1.948 & 1.775 & 1.560 \\
\hline PEG & 28.623 & 31.467 & 33.826 & 35.872 & 37.882 \\
\hline \multicolumn{6}{|c|}{ Bottom phase } \\
\hline Salt & 11.937 & 13.253 & 14.360 & 15.169 & 16.300 \\
\hline PEG & 0.420 & 0.422 & 0.260 & 0.156 & 0.190 \\
\hline \multicolumn{6}{|c|}{$T L L$} \\
\hline & 0.262 & 0.294 & 0.336 & 0.368 & 0.389 \\
\hline \multicolumn{6}{|c|}{$K$} \\
\hline $\mathrm{GLY}^{b}$ & $6.8633 \pm 0.0982$ & $8.5573 \pm 0.0741$ & $11.6034 \pm 0.2197$ & $14.3687 \pm 0.2429$ & $18.3008 \pm 0.1927$ \\
\hline $\mathrm{ALA}^{b}$ & $7.9992 \pm 0.1520$ & $10.4896 \pm 0.0428$ & $13.3266 \pm 0.2318$ & $16.7941 \pm 0.1353$ & $22.1336 \pm 0.2616$ \\
\hline $\mathrm{VAL}^{b}$ & $13.3540 \pm 0.2057$ & $16.9456 \pm 0.1866$ & $23.5755 \pm 0.2458$ & $29.3976 \pm 0.2940$ & $36.3451 \pm 0.3494$ \\
\hline $\mathrm{LEU}^{b}$ & $17.8506 \pm 0.2544$ & $24.1071 \pm 0.2646$ & $34.0966 \pm 0.3199$ & $45.2220 \pm 0.4450$ & $61.1531 \pm 0.5998$ \\
\hline \multirow{3}{*}{\multicolumn{6}{|c|}{$\begin{array}{c}(P E G+\text { magnesium sulfate }) \\
\text { Composition } \% w / w[6] \\
\text { Overall }\end{array}$}} \\
\hline & & & & & \\
\hline & & & & & \\
\hline Salt & 7.51 & 8.00 & 8.49 & 9.12 & 9.56 \\
\hline PEG & 13.99 & 15.00 & 15.98 & 16.94 & 17.98 \\
\hline \multicolumn{6}{|c|}{ Top phase } \\
\hline Salt & 2.011 & 1.526 & 1.310 & 1.042 & 0.994 \\
\hline PEG & 28.521 & 31.233 & 33.767 & 36.274 & 38.137 \\
\hline \multicolumn{6}{|c|}{ Bottom phase } \\
\hline Salt & 12.947 & 13.858 & 14.899 & 16.142 & 18.372 \\
\hline PEG & 2.805 & 3.057 & 3.387 & 3.489 & 2.588 \\
\hline \multicolumn{6}{|c|}{$T L L$} \\
\hline & 0.279 & 0.308 & 0.333 & 0.361 & 0.396 \\
\hline \multicolumn{6}{|c|}{$K$} \\
\hline $\mathrm{GLY}^{b}$ & $4.1614 \pm 0.0420$ & $4.8519 \pm 0.0744$ & $5.9708 \pm 0.0307$ & $7.5178 \pm 0.0849$ & $8.9371 \pm 0.1365$ \\
\hline $\mathrm{ALA}^{b}$ & $4.8423 \pm 0.0664$ & $5.7878 \pm 0.0581$ & $7.6339 \pm 0.0310$ & $9.8875 \pm 0.0817$ & $11.8828 \pm 0.1356$ \\
\hline $\mathrm{VAL}^{b}$ & $7.3331 \pm 0.0471$ & $9.1884 \pm 0.1073$ & $11.8058 \pm 0.0590$ & $16.2851 \pm 0.1807$ & $20.9377 \pm 0.1805$ \\
\hline $\mathrm{LEU}^{b}$ & $9.2729 \pm 0.1070$ & $11.9525 \pm 0.1751$ & $16.4753 \pm 0.0691$ & $23.0100 \pm 0.2884$ & $30.6127 \pm 0.3269$ \\
\hline
\end{tabular}

${ }^{a}$ Standard uncertainties $u$ are $u(T)=0.1 \mathrm{~K}, u(p)=0.005 \mathrm{MPa}, u(x)=0.0005$ (mass fractions).

${ }^{b}$ Mass ratio of DNP-amino acid to total mass ATPS from $4 \times 10^{-5}$ to $2 \times 10^{-4}$.

Additionally, constant $b$ assumes very small values, close to zero (average $b=0.0042$ ). This assures that the partition coefficients are independent of the amino acid composition, and that no interactions affect the partitioning process [31].

Table 2 also presents the values for the tie-line lengths, TLL, which are a measure of the differences in phase composition, defined as [26,31]:

$T L L=\sqrt{\left(x_{\text {top }}-x_{\text {bottom }}\right)^{2}+\left(y_{\text {top }}-y_{\text {bottom }}\right)^{2}}$,

where $x$ and $y$ indicate respectively salt and polymer mass fractions. When increasing concentration of both, salt and polymer, TLL reaches a higher value.

Eiteman and Gainer [32] reported that magnesium cation captures more water and makes the behavior of the saline phase more complicated. Comparing the composition of the bottom phase [6] for both systems studied in this work, (PEG $8000+\mathrm{Na}_{2} \mathrm{SO}_{4}$ ) and $\left(\mathrm{PEG} 8000+\mathrm{MgSO}_{4}\right)$, the bottom phase of the second system is richer in water, leading to a higher volume of this phase, and smaller $K$ values. This is because of the higher solubility of $\mathrm{MgSO}_{4}$ in water.

Figure 1 shows the logarithms of partition coefficients, $\ln K$, represented against the tie-line lengths $(T L L)$. It can be observed that partition coefficients are a linear function of the $T L L, \ln K$ increase with the TLL linearly, which is in agreement with previous studies for different ATPS $[26,31,34,35]$. This can be expressed by: $\ln K=\alpha \cdot T L L$

where $\alpha$ is a constant that traduces the effect of the equilibrium phases composition. For the origin critical point (in the graph), $T L L=0$, ATPS phases have the same composition and therefore $\ln K=0$. In both studied systems, the top phase is richer in PEG, while the sulfate salt is in major amount in the bottom phase. Considering the hydrophobic target of the four studied DNP-amino acids, they are strongly partitioned to the top phase (with increasing of the TLL).

Figure 2 shows the logarithms of the partition coefficients $K$ against the average equivalent number of methylene groups, $n$ $\left(\mathrm{CH}_{2}\right)$ that are present in the aliphatic side chain of the homologous DNP-amino acids. It is worth remarking that values of $n(\mathrm{CH})_{2}$ are different from the real alkyl chain length and were adjusted according to [29], and their suitability has been demonstrated for ATPS with polymer and salt $[30,31]$.

From figure 2, linearity for each tie-line is observed, according to [29]:

$\ln K_{i}=C+E \cdot n\left(\mathrm{CH}_{2}\right)$

where $\ln K_{i}$ represents the natural logarithm of partition coefficient $K$ of solute $i, n\left(\mathrm{CH}_{2}\right)$ is the equivalent number of $\mathrm{CH}_{2}$ groups of a given solute (determining the length of the aliphatic chain), parameter $C$ constitutes the total contribution of the non-alkyl part of the solute structure and corresponds to the intercept in figure 2, E spec- 
(a)

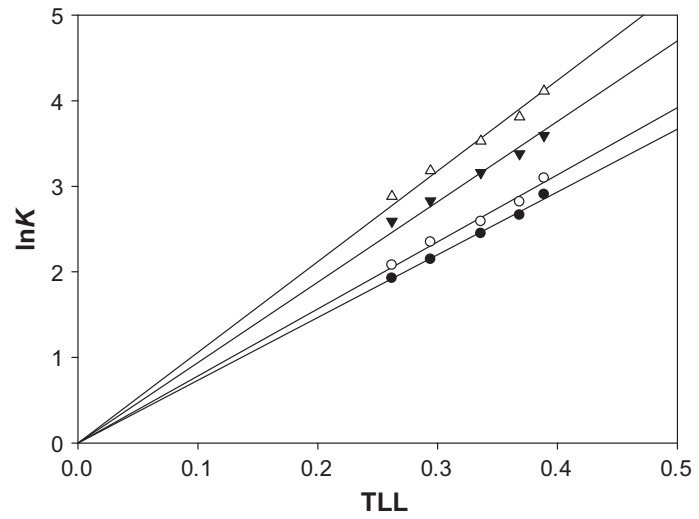

(b)

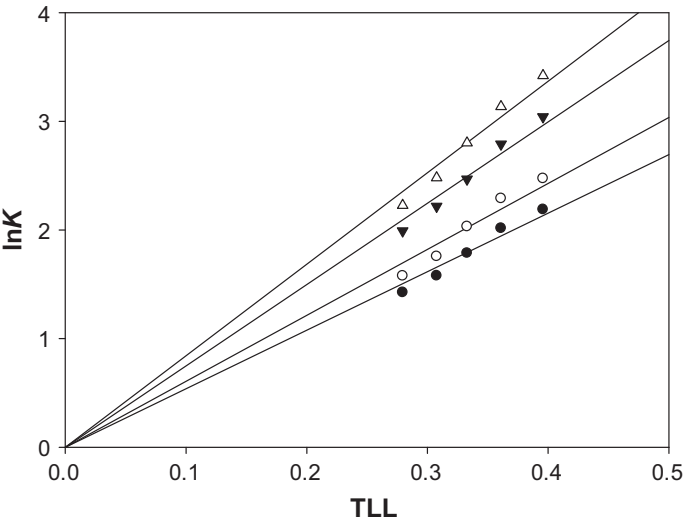

FIGURE 1. Logarithm of partition coefficients of the DNP-amino acids

Gly; $\bigcirc$ Ala:

Val; $\triangle$ Leu) as a function of TLL for the two ATPS studied: (a) (PEG $8000+$ sodium sulfate), (b) (PEG 8000 + magnesium sulfate).

(a)

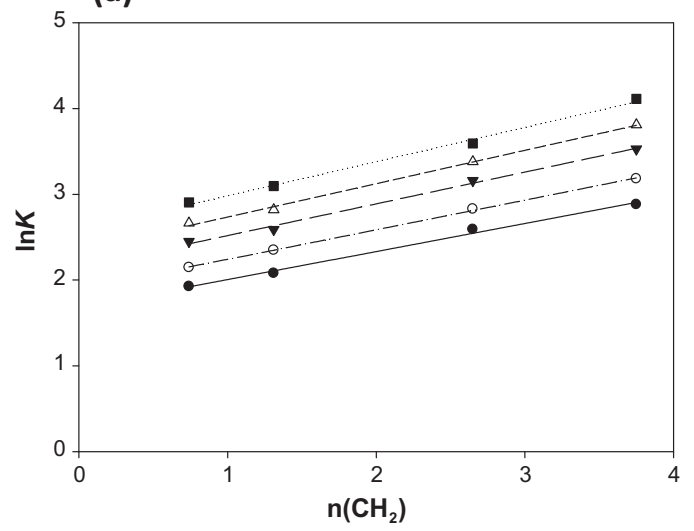

(b)

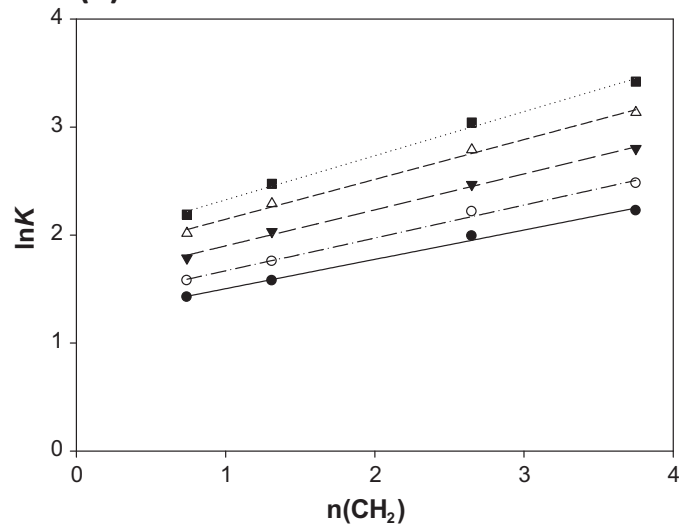

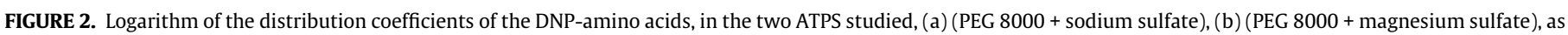
a function of the average number of methylene groups. Tie lines: $\bullet$ (1), $\bigcirc$ (2), $\boldsymbol{\nabla}$ (3), $\triangle$ (4), $\mathbf{\square}(5)$.

ifies the contribution of every methylene group to the distribution coefficient and represents the slope of a straight lines in figure 2. Parameters $C, E$ with the corresponding $r^{2}$ values obtained by linear regression are given in table 3.

Figure 3 shows the representation of both parameters as a function of $T L L$ for the two systems studied. Values of coefficients $C$ and $E$ for the five $T L L$ studied in the system (PEG $8000+\mathrm{Na}_{2} \mathrm{SO}_{4}$ ) were compared with data reported in the previous publications already

TABLE 3

Values of $\Delta G^{*}\left(\mathrm{CH}_{2}\right)$ and parameters $C$ and $E$ obtained for five tie-lines of the two (PEG + sulfate) ATPS studied.

\begin{tabular}{lllllll}
\hline Tie line & $C$ & $E$ & $r^{2}$ & $\Delta G^{*}\left(\mathrm{CH}_{2}\right) /\left(\mathrm{kJ} \cdot \mathrm{mol}^{-1}\right)$ \\
\hline \multicolumn{7}{c}{ PEG + sodium sulfate } \\
I & 1.678 & 0.327 & 0.994 & -0.812 & \pm & 0.018 \\
II & 1.898 & 0.346 & 0.999 & -0.856 & \pm & 0.006 \\
III & 2.151 & 0.370 & 0.995 & -0.917 & \pm & 0.018 \\
IV & 2.349 & 0.389 & 0.997 & -0.964 & \pm & 0.014 \\
V & 2.586 & 0.399 & 0.995 & -0.988 & \pm & 0.020 \\
& 1.231 & 0.277 & 0.994 & -0.674 & \pm & 0.015 \\
I & 1.364 & 0.305 & 0.994 & -0.757 & \pm & 0.016 \\
II & 1.569 & 0.335 & 0.997 & -0.826 & \pm & 0.014 \\
III & 1.780 & 0.369 & 0.995 & -0.914 & \pm & 0.019 \\
IV & 1.920 & 0.405 & 0.996 & -1.012 & \pm & 0.019 \\
V & \multicolumn{7}{c}{ PEG } & \multicolumn{7}{c}{ magnesium sulfate } & \\
\hline
\end{tabular}

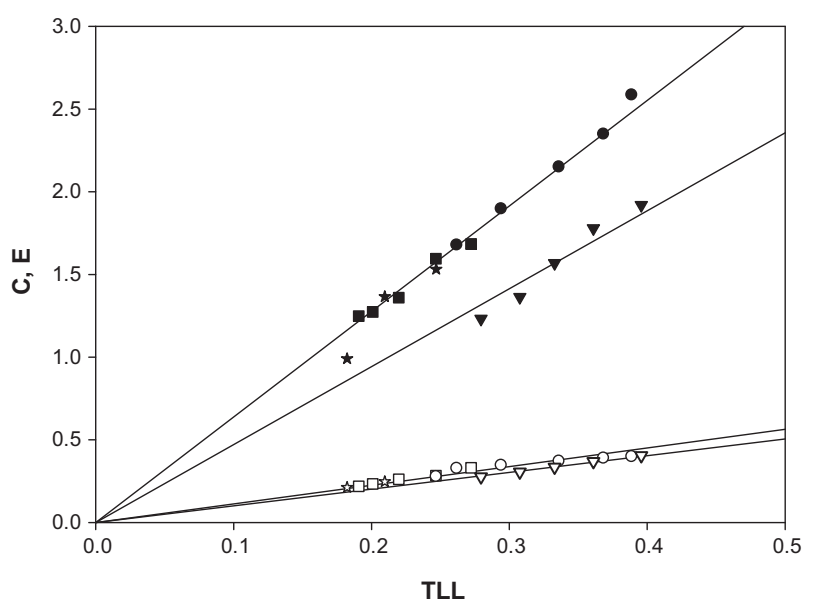

FIGURE 3. $C, E$ coefficients obtained in this work for two ATPS, (PEG 8000 + sodium sulfate) $(\bullet C, \bigcirc E)$ and (PEG $8000+$ magnesium sulfate) $(\boldsymbol{\nabla}, \nabla E)$; system of (PEG $8000+$ sodium sulfate) compared with the data from previous studies: ( $\square C, \square E$ ) [26] and $(\star C$, s $E)$ [27].

mentioned [26,27]. Coefficients, $C$ and $E$, which meaning was given above, are in agreement for all reported studies [26,27]. Straight lines were obtained, as shown. 
The Gibbs energy of transfer $(\Delta G)$ of a component $i$, from one phase to another, may be associated with its partition coefficients, respectively $[29,31,35]$ :

$\Delta G=-R \cdot T \cdot \ln K_{i}$

where $R$ is the universal gas constant, and $T$ is the absolute temperature $[\mathrm{K}]$.

$\Delta G^{*}\left(\mathrm{CH}_{2}\right)$ can be calculated by combining equations (5) and (6) and using parameter $E$ as the value of changes in affinities of the two phases for a $\mathrm{CH}_{2}$ group:

$\Delta G^{*}\left(\mathrm{CH}_{2}\right)=-R T E$.

The values of $\Delta G^{*}\left(\mathrm{CH}_{2}\right)$ are presented in table 3. Positive values of $E$ and negative values of $\Delta G$ prove that the top phase (polymerrich) is more hydrophobic than the bottom phase (salt-rich).

The system of (PEG 8000 + sodium sulfate) presents more negative values of $\Delta G^{*}\left(\mathrm{CH}_{2}\right)$ than ATPS of (PEG $8000+$ magnesium sulfate), so the first has a larger relative hydrophobicity. It means that the ATPS of sodium sulfate is more efficient for partitioning. System with sodium salt provides also higher slope than magnesium, which is caused by the differences among the compositions of the equilibrium phases.

Figure 4 presents the representation of $\Delta G^{*}\left(\mathrm{CH}_{2}\right)$ against the TLL for both systems studied. Straight lines obtained $\left(r^{2}=0,9994\right.$ for system with sodium sulfate and $r^{2}=0,9997$ for system with magnesium sulfate) confirm that $\Delta G^{*}\left(\mathrm{CH}_{2}\right)$, and therefore hydrophobicity, increase linearly with the increase of $T L L$, as reported in the literature [26,31].

The comparison of the $\Delta G^{*}\left(\mathrm{CH}_{2}\right)$ values calculated in this study for the five TLL in the system (PEG $8000+\mathrm{Na}_{2} \mathrm{SO}_{4}$ ) with $\Delta G^{*}\left(\mathrm{CH}_{2}\right)$ reported previously in the literature for the same system with different TLL values is presented on figure 5. The experimental data from literature were $[26,27]$ obtained at $T=296.15 \mathrm{~K}$ and buffers were used to maintain $\mathrm{pH}$ constant. The temperature of our study ( $298.15 \mathrm{~K})$ is slightly different and buffer was not used. It is possible to observe that although there is a difference in the slope, this is not significant. This means that the addition of buffer does not have a strong influence on the hydrophobicity for this system.

In a previous work reported in the literature [32] for the system $\left(\right.$ PEG $\left.8000+\mathrm{MgSO}_{4}\right)$ the values of partition coefficients and tie-line lengths are not given, and therefore there is no possibility to compare our results with those, in the same extent like it was done for the system of (PEG $8000+\mathrm{Na}_{2} \mathrm{SO}_{4}$ ). Values of the observed relative amino acid hydrophobicity followed the hydrophobicity scale in order: Gly < Ala < Leu and as it was expected, they were dependent

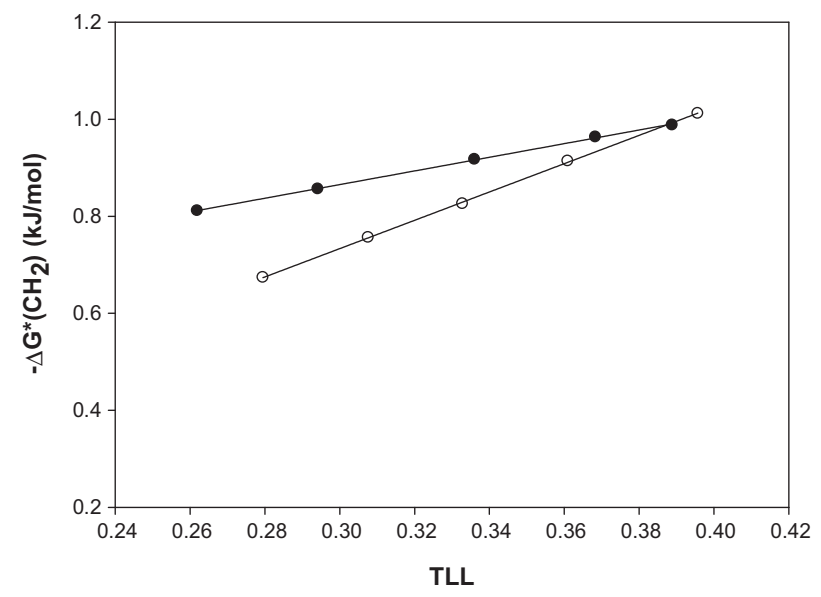

FIGURE 4. Values of $\Delta G^{*}\left(\mathrm{CH}_{2}\right)$ as a function of the TLL for the two ATPS studied $\mathrm{PEG}+$ sodium sulfate, $\bigcirc \mathrm{PEG}+$ magnesium sulfate).

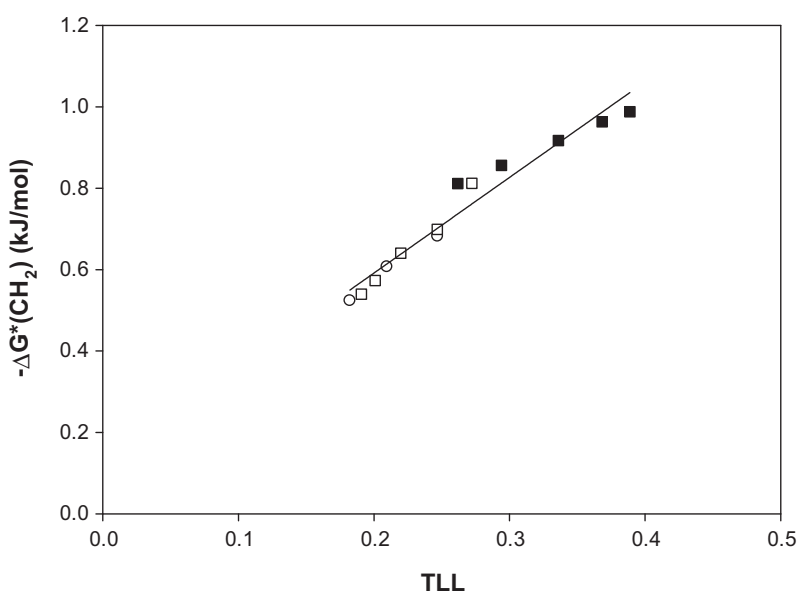

FIGURE 5. Comparison of values of $\Delta G^{*}\left(\mathrm{CH}_{2}\right)$ as a function of the TLL in PEG 8000$\mathrm{Na}_{2} \mathrm{SO}_{4}$ for the present research ( $\left.\mathbf{\square}\right)$ and two previous studies ( $\square$ [26], $\bigcirc$ [27]).

on the partition coefficients values. In this work, hydrophobicities of the phases were studied. It was also shown that values of partition coefficients increase while the number of $\mathrm{CH}_{2}$ groups increase, in the same order, as follows: Gly $<$ Ala $<$ Val $<$ Leu.

\section{Conclusions}

Partition coefficients for four DNP-amino acids: DNP-Gly, DNPAla, DNP-Val, DNP-Leu were obtained in five tie-lines of (PEG 8000 $+\mathrm{Na}_{2} \mathrm{SO}_{4}$ ) and (PEG $8000+\mathrm{MgSO}_{4}$ ) at $T=298.15 \mathrm{~K}$, based on an experimental technique previously reported [31]. Values of the partition coefficients increase as the tie-line lengths increase, what is in agreement with other studies from the literature. They are higher for the system of PEG 8000 with sodium sulfate. Concerning the $\Delta G^{*}\left(\mathrm{CH}_{2}\right)$ calculations, it indicates that the hydrophobicity of the phases is higher for the system formed by sodium sulfate. It assumes that for the conditions used in the experiments, this ATPS is more suitable for the amino acids partitioning. Smaller solubility of sodium sulfate comparing to magnesium sulfate can have impact on higher values of the partition coefficients for system of $\left(\right.$ PEG $\left.8000+\mathrm{Na}_{2} \mathrm{SO}_{4}\right)$. The amino acids studied in this work have higher affinity to the top phase - polymer rich.

\section{Acknowledgements}

This work was partially supported by FCT/MEC and FEDER under Programe PT2020 (Project UID/EQU/50020/2013), and cofinanced by QREN, ON2 and FEDER (Projects NORTE-07-0162FEDER-000050 and NORTE-07-0124-FEDER-0000011), for which the authors are thankful.

SCS also acknowledges her post-doc grant (SFRH/ BPD/88584/2012) from FCT.

The authors are grateful to Dr Pedro Madeira and Dr Luísa Ferreira for helpful suggestions.

\section{References}

[1] E. Huenupi, A. Gomez, B.A. Andrews, J.A. Asenjo, J. Chem. Technol. Biotechnol. 74 (1999) 256-263.

[2] J.A. Asenjo, B.A. Andrews, J. Chromatogr. A 1218 (2011) 8826-8835.

[3] A.P. De Los Rios, F.J. Hernandez-Fernandez, Ionic Liquids in Separation Technology, Netherlands, 2014, pp. 208.

[4] P.A. Albertsson, Partitioning of Cell Particles and Macromolecules, WileyInterscience, New York, 1986. pp. 8-38.

[5] J.L. Cleland, C. Hedgepeth, D.I. Wang, J. Biol. Chem. 267 (1992) 13327-13334.

[6] E.V.C. Cunha, M. Aznar, J. Chem. Eng. Data 54 (2009) 3242-3246.

[7] S.M. Snyder, K.D. Cole, D.C. Szlag, J. Chem. Eng. Data 37 (1992) 268-274. 
8] N. Voros, P. Proust, A. Fredenslund, Fluid Phase Equilib. 90 (1993) 333-353.

[9] A. Salabat, Fluid Phase Equilib. 187 (2001) 489-498.

[10] L.H.M. da Silva, J.S.R. Coimbra, A.J.A. Meirelles, J. Chem. Eng. Data 42 (1997) $398-401$.

[11] M.T. Zafarani-Moattar, R. Sadeghi, Fluid Phase Equilib, 47 (2002) 525-528.

[12] R.A.G. Se, M. Aznar, J. Chem. Eng. Data 47 (2002) 1401-1405.

[13] M.E. Taboada, J.A. Asenjo, B.A. Andrews, Fluid Phase Equilib. 180 (2001) 273280.

[14] B. Ma, M. Hu, S. Li, Y. Jiang, Z. Liu, J. Chem. Eng. Data 50 (2005) 792-795.

[15] M.E. Taboada, H.R. Galleguillos, T.A. Graber, S. Bolado, J. Chem. Eng. Data 50 (2005) 264-269.

[16] M.H. Salamanca, J.C. Merchuk, B.A. Andrews, J.A. Asenjo, J. Chromatogr. B Biomed. Sci. Appl. 711 (1998) 319-329.

[17] J.P. Martins, C.P. Carvalho, L.H.M. da Silva, J.S.R. Coimbra, M.C.H. da Silva, G.D. Rodrigues, L.A. Minim, J. Chem. Eng. Data 53 (2008) 238-241.

[18] J.P. Martins, F.C. de Oliveira, J.S.R. Coimbra, L.H.M. da Silva, M.C.H. da Silva, I.S. B. do Nascimento, J. Chem. Eng. Data 53 (2008) 2441-2443.

[19] J.P. Martins, J.S.R. Coimbra, F.C. de Oliveira, G. Sanaiotti, C.A.S. da Silva, L.H.M. da Silva, M.C.H. da Silva, J. Chem. Eng. Data 55 (2010) 1247-1251.

[20] A.M. Goja, H. Yang, M. Cui, C. Li, J. Bioproces. Biotechniq. 4 (1) (2013) 1-8.

[21] S. Raja, V.R. Murty, V. Thivaharan, V. Rajasekar, V. Ramesh, Sci. Technol. 1 (2011) 7-16.

[22] B.D. Castro, M. Aznar, Braz. J. Chem. Eng. 22 (2005) 463-470.

[23] L.A. Ferreira, J.A. Teixeira, J. Chem. Eng. Data 56 (2011) 133-137.
[24] L.A. Ferreira, P. Parpot, J.A. Teixeira, L.M. Mikheeva, B.Y. Zaslavsky, J. Chromatogr. A 1220 (2012) 14-20.

[25] P. Gonzalez-Tello, F. Camacho, G. Blazquez, F.J. Alarcon, J. Chem. Eng. Data 41 (1996) 1333-1336.

[26] O. Rodriguez, S.C. Silvério, P.P. Madeira, J.A. Teixeira, E.A. Macedo, Ind. Eng. Chem. Res. 46 (2007) 8199-8204.

[27] L.A. Ferreira, J.A. Teixeira, J. Chem. Thermodyn. 43 (2011) 1299-1304.

$28]$ N.R. da Silva, L.A. Ferreira, L.M. Mikheeva, J.A. Teixeira, J. Chromatogr. A 1337 (2014) 3-8.

[29] B.Y. Zaslavsky, Aqueous Two-Phase Partitioning: Physical Chemistry and Bioanalytical Applications, Marcel Dekker, New York, 1995.

[30] P.P. Madeira, J.A. Teixeira, E.A. Macedo, L.M. Mikheeva, B.Y. Zaslavsky, J. Chromatogr. A 1185 (2008) 85-92.

[31] S.C. Silvério, O. Rodriguez, J.A. Teixeira, E.A. Macedo, J. Chem. Thermodyn. 42 (2010) 1063-1069.

[32] M.A. Eiteman, J.L. Gainer, Biotechnol. Progr. 6 (1990) 479-484.

[33] J. Chen, S.K. Spear, J.G. Huddleston, R.D. Rogers, Green Chem. 7 (2005) 64-82.

[34] H.D. Willauer, J.G. Huddleston, R.D. Rogers, Ind. Eng. Chem. Res. 41 (2002 1892-1904.

[35] H.D. Willauer, J.G. Huddleston, R.D. Rogers, Ind. Eng. Chem. Res. 41 (2002) 2591-2601.

JCT 15-282 